\title{
Ocupar, Resistir e Produzir: o pré-assentamento Irmã Dorothy, em Barbosa Ferraz - PR
}

\author{
Occupy, Resist and Produce: the pre-settlement Sister Dorothy, in Barbosa \\ Ferraz - PR \\ Ocupar, Resistir y Producir: el pre-asentamiento Hermana Dorothy, en Barbosa \\ Ferraz - PR
}

\author{
Aline Albuquerque Jorge ${ }^{1}$ \\ Elpídio Serra ${ }^{2}$
}

\begin{abstract}
RESUMO: Ocupar, produzir, resistir. Foi com tais propósitos que aproximadamente 50 famílias camponesas ligadas ao MST - Movimento dos Trabalhadores Rurais Sem-Terra - tomaram posse, em 2005, da Fazenda São Paulo, no município de Barbosa Ferraz, região centro-ocidental do Paraná e lá se mantêm, como que desafiando sucessivas ordens de despejo emitidas pelo Poder Judiciário. A área ocupada, de 573,20 hectares, foi dividida em lotes individuais pelos próprios camponeses, que deram ao acampamento o status de pré-assentamento rural, e o batizaram com o nome da religiosa Irmã Dorothy. Estudar o processo de luta pela terra dos camponeses de Barbosa Ferraz é o objetivo deste trabalho, no qual se procurou valorizar as estratégias e anseios da luta camponesa, a receptividade da comunidade local e regional e os caminhos percorridos nas esferas do Poder Judiciário, tanto por parte do antigo proprietário pela reintegração de posse, como pelos apoiadores dos trabalhadores acampados, pela efetivação de um projeto de reforma agrária.
\end{abstract}

PALAVRAS-CHAVE: Movimento social. Reforma agrária. Território.

ABSTRACT: Occupy, produce and resist. With these intents, approximately 50 peasant families connected with MST - the Landless Rural Workers' Movement in Brazil - took possession of the São Paulo Farm in 2005, in the municipality of Barbosa Ferraz, in the central-western region of Paraná, and who challenged successive eviction orders issued by the Judiciary. The occupied area of 573,20 hectares was divided into individual lots by the peasants themselves, who gave the camp the status of rural pre-settlement, and named it Sister Dorothy. Studying the process of struggle for land of the peasants from Barbosa Ferraz is the objective of this work. It is sought to value the strategies and anxieties of the peasant struggle, the receptivity of the local and regional community and the paths covered in the spheres of the Judiciary, both by the former owner for the reintegration of possession and the supporters of the workers camped, for the implementation of an agrarian reform project.

\footnotetext{
${ }^{1}$ Graduada em Geografia pela Universidade Estadual de Maringá (UEM), mestranda em Geografia pela Universidade Estadual de Maringá. Endereço: Av. Colombo, 5790, Jardim Universitário, Maringá - PR, e-mail: albuquerquealine312@gmail.com.

${ }^{2}$ Graduado em Geografia pela Universidade Estadual de Maringá (UEM), doutor em Organização do Espaço Urbano e Rural pela Universidade Estadual Paulista Júlio Mesquita Filho, Professor Associado da Universidade Estadual de Maringá. Endereço: Av. Colombo, 5790, Jardim Universitário, Maringá - PR, e-mail: serraelpidio@gmail.com.
} 
KEYWORDS: Social movement. Land reform. Territory.

RESUMEN: Ocupar, producir, resistir. Con estos propositos, alrededor de 50 familias de campesinos vinculados al MST - Movimiento de los Trabajadores Rurales Sin Tierra - tomaron posesión, en 2005, de la Hacienda São Paulo, en la localidad de Barbosa Ferraz, región centro occidental de Paraná y allí se mantienen, desafiando sucesivas órdenes de desalojo emitidas por el Poder Judicial. El área ocupada, de 573,20 hectáreas, se dividió en parcelas individuales por los mismos campesinos, donde se le ha asignado el estatus de pre asentamiento rural y que se bautizó con el nombre de la monja Hermana Dorothy. Estudiar el proceso de lucha por la tierra de los campesinos de Barbosa Ferraz es el objetivo de este artículo, que intenta valorizar las estrategias y anhelos de la lucha campesina, la receptividad de la comunidad local y regional así como los caminos recorridos en la esfera judicial, tanto por parte del antiguo propietario por la reintegración de la posesión, como por los partidarios de los trabajadores acampados por la celebración de un proyecto definitivo de reforma agraria.

PALABRAS-CLAVE: Movimiento Social; Reforma Agraria; Territorio.

\section{INTRODUÇÃO}

Localizado no município de Barbosa Ferraz, na mesorregião centro ocidental, o préassentamento Irmã Dorothy simboliza a luta pela terra e pelas condições de sobrevivência de famílias camponesas do Paraná. Da mesma forma simboliza, no contexto da luta, as dificuldades e os desafios que permeiam a concretização de assentamentos rurais em projetos de reforma agrária no Estado'.

O pré-assentamento, assim considerado pelos próprios camponeses que ocuparam a área de 573,20 hectares da Fazenda São Paulo em 2005, tem toda uma trajetória de conflito, sendo por este motivo escolhido para sustentar o presente trabalho. O estudo, desde o início da ocupação até o processo de expulsão dos camponeses, através de medidas judiciais lavradas em ações de reintegração de posse, retrata um ambiente particular de conflito rural e ao mesmo tempo a realidade da luta camponesa em todo o país.

Desta forma, para entender o conflito social que envolve as famílias do préassentamento, faz-se necessário compreender o desenvolvimento histórico dos mecanismos de acesso à terra no Brasil, bem como as consequências desse processo envolvendo as relações capitalistas no campo.

É fato que, desde o período colonial, a estrutura agrária brasileira se baseia na grande propriedade improdutiva ou produtora de monoculturas de exportação. A grande propriedade, associada ao trabalho servil e, em seguida, à mão de obra dos trabalhadores importados (a corrente migratória), se constituirá no modelo fundiário brasileiro que tenta ser rompido a partir das bases sociais. É nesta parte que se insere a luta das famílias que compõem o pré-assentamento estudado. 
A concentração fundiária, originada no período colonial, nos períodos mais recentes ganhou força com o advento do novo modelo agrícola, implantado a partir de 1950. A modernização agrícola, dependente de insumos e de máquinas agrícolas, para ser consolidada, passou a depender de áreas maiores para o plantio, o que levou os proprietários rurais a ampliarem suas áreas de cultivo.

As novas tecnologias atenderam aos interesses do mercado externo por duas vias: ao mesmo tempo em que o Brasil se tornou mercado consumidor dos produtos fabricados pelos países industrializados, pôde, por meio desse processo, aumentar a produção dos gêneros voltados à exportação.

Com relação aos aspectos sociais, o novo modelo teve vários desdobramentos, tais como o aumento da desigualdade social, o desemprego e a expropriação dos camponeses, cuja mão de obra foi substituída pela máquina.

Parcela significativa dos trabalhadores expulsos e expropriados somou aos movimentos sociais, entre estes, o MST - Movimento dos Trabalhadores Rurais Sem-Terra que, desde sua formação, luta pelo acesso a terra, pela reforma agrária e por transformações sociais.

Fazem parte desse contexto as 33 famílias que atualmente compõem o préassentamento Irmã Dorothy. Esses trabalhadores são considerados camponeses, pois são pessoas vinculadas às atividades do campo e que, devido à expulsão e expropriação, vivenciam a luta permanente pela conquista da terra.

Para tratar todas estas questões, valorizando a trajetória de luta dos trabalhadores, o trabalho conta com uma abordagem qualitativa e com uma fundamentação teórica que trata dos temas colonização, modernização agrícola e reforma agrária. Entre as publicações utilizadas estão as de Prado Júnior (1983), Serra (1992), Silva (1985), Stedile e Fernandes (2012), e Oliveira (2007).

Além disso, esse trabalho utiliza como fontes informações de entrevistas realizadas através de perguntas abertas, direcionadas as famílias do pré-assentamento e a representantes e lideranças do Movimento Sem-Terra. Também são utilizados documentos anexados aos dois processos que envolvem o conflito: um na Justiça Estadual e outro na Federal. Essas ações judiciais se justificam diante do fato de que o proprietário da área em disputa ajuizou pedido de reintegração de posse, contestado pelos trabalhadores.

\section{OS MECANISMOS DE APROPRIAÇÃO DE TERRA E O LATIFÚNDIO NO BRASIL}

Importante salientar que o cenário agrário atual, do qual faz parte o pré-assentamento Irmã Dorothy, é resultado de processos históricos envolvendo a questão agrária brasileira. Diante disso, não é possível entender os conflitos no campo sem se realizar um resgate 
histórico que mostre como se desenvolveram os mecanismos de apropriação de terra e em benefício de quem.

É oportuno, portanto, retroceder e resgatar, mesmo que sinteticamente, como foi a dominação do território brasileiro pelos colonizadores europeus, motivados pelas possibilidades contidas nas zonas de clima tropical, que favoreciam a exploração de produtos cobiçados no período das grandes navegações.

A penetração e ocupação do território ocorreram gradativamente, conforme se desenvolviam os ciclos econômicos. Primeiro, o pau brasil, depois, a cana, o ouro, o algodão, o café e a borracha. Todos esses produtos atenderam às necessidades do comércio europeu e justificaram a apropriação da terra, invariavelmente em grandes áreas (PRADO JÚNIOR, 1983).

O desenvolvimento da maior parte dessas atividades foi baseado no trabalho escravo. O primeiro a ser escravizado foi o índio, mais tarde, foi a vez do negro africano, trazido para o Brasil para substituir o nativo (SILVA, 1985).

A administração territorial foi estabelecida pelas Capitanias Hereditárias. Ao todo, foram 12 os escolhidos pelo rei, os quais receberam poderes soberanos sobre largas porções de terras. Essas concessões foram a forma de se conquistar sujeitos dispostos a aventurar-se pela colônia tropical. Nesse sentido, assevera Prado Júnior (1983, p. 19):

As doações foram em regra muito grandes, medindo-se os lotes por muitas léguas. O que é compreensível: sobravam as terras, e as ambições daqueles pioneiros recrutados a tanto custo, não se contentariam evidentemente com propriedades pequenas; não era a posição de modestos camponeses que aspiravam no novo mundo, mas de grandes senhores e latifundiários. Além disso, e sobretudo por isso, há um fator material que determina este tipo de propriedade fundiária. A cultura da cana somente se prestava, economicamente, a grandes plantações. Já para desbravar convenientemente o terreno (tarefa custosa neste meio tropical e virgem tão hostil ao homem) tornava-se necessário o esforço reunido de muitos trabalhadores; não era empresa para pequenos proprietários isolados. Isto feito, a plantação, a colheita e o transporte do produto até os engenhos onde se preparava o açúcar, só se tornava rendoso quando realizado em grandes volumes.

Nas capitanias hereditárias se desenvolveu o sistema de sesmarias, a primeira forma jurídica de apropriação de terra, baseada na larga distribuição de propriedades a camadas privilegiadas da sociedade, como nobres, militares e navegadores, conferindo à população menos favorecida a condição de pequenos posseiros de terras que ainda não haviam sido reclamadas (SERRA, 2009).

A posse das sesmarias estava relacionada com a demonstração de influência e poder político. Nesse sistema, formavam-se grandes propriedades, sobretudo, quando, em uma mesma família, mais de uma pessoa adquiria título de sesmeiro. 
Na ótica de Prado Júnior (1983), essas circunstâncias determinaram o tipo de exploração agrária adotada no Brasil: a grande propriedade, associada à monocultura e à mão de obra escrava.

Adquirir sesmaria estava ligado à demonstração de status, em muitas situações a exploração econômica não ocorria, o que desdobrou na estreita identificação desse mecanismo com a propriedade improdutiva (SERRA, 1992).

Em 1822, esse sistema foi extinto. Nas duas décadas seguintes, não surgiu nenhuma legislação que regulasse a distribuição de terras devolutas. A posse passou a ser o meio adotado, beneficiando os sujeitos ligados ao poder dominante, que "[...] a pretexto de terem prestado algum serviço de utilidade pública, acabavam se apropriando de grandes extensões territoriais" (SERRA, 2009, p. 3).

Essa fase durou até 1850, quando passou a vigorar a Lei de Terras, estabelecendo que, a partir de então, a apropriação de terras ocorreria somente por meio da compra. Esse processo não alterou a estrutura fundiária, ou seja, conservou os interesses dos antigos sesmeiros e posseiros (SILVA, 1985).

Em linhas gerais, as características que se desenvolveram no Brasil colônia também se fazem presentes no cenário agrário atual, agora com acessórios que aceleram a exploração capitalista. O modelo produtivo ainda favorece o mercado externo, bem como privilegia a grande propriedade. Adiciona-se a isso a técnica, que permeia o campo, acelerando a produção e substituindo o trabalho humano pela máquina.

Esse processo ocorreu, de forma intensa, a partir de 1950, quando o Brasil se inseriu na modernização agrícola, ou seja, quando incorporou um novo modelo composto por maquinários, adubos químicos e defensivos agrícolas, servindo de mercado consumidor das tecnologias produzidas pelos países industrializados.

A substituição de culturas foi parte mestre desse processo. A soja foi introduzida na agricultura, sempre em alternância com outros plantios, tais como o milho e o trigo. No Paraná, como aponta Fleischfresser (1988), essas lavouras temporárias substituíram a cafeicultura.

O novo modelo transformou a paisagem rural: a casa, o pomar, a horta e os animais saíram de cena, então o que se enxergava eram "mares de soja", que ora também eram de milho, ou, em regiões com solos mais arenosos, de cana.

José Graziano da Silva (1981, p. 29) denominou esse processo de "modernização dolorosa", destacando que as unidades de produção se tornaram cada vez maiores, desdobrando na "[...] deterioração da distribuição da renda no setor agrícola." O tamanho das unidades foi fruto da concentração fundiária e da crescente mecanização da lavoura, que só era economicamente viável quando empregada em largas porções de terra. 
Nesse sentido, a máquina representou o aprofundamento das relações capitalistas na agricultura e ampliou a desigualdade social, uma vez que aumentou o nível de exigência e diminuiu o período de ocupação da mão de obra, refletindo na expulsão e expropriação dos camponeses. Logo,

\begin{abstract}
A mecanização da lavoura e a introdução, digamos, de uma agricultura com características mais capitalistas expulsaram do campo, de uma maneira muito rápida, grandes contingentes populacionais naquela década. Eram famílias que viviam como arrendatárias, parceiras ou filhos de agricultores que recebiam um lote desmembrado da já pequena propriedade agrícola de seus pais. Foi um período em que a natureza principal da agricultura era o uso intensivo de mão de obra. Não sei se é justo dizer que era uma agricultura atrasada - penso que aqui não cabem comparações -, que utilizavam muita mão de obra e pouca mecanização. Com a entrada da mecanização, liberou-se um enorme contingente de pessoas (STEDILE; FERNANDES, 2012, p. 17 - 18).
\end{abstract}

Para essa massa de trabalhadores expropriados restaram poucas alternativas: multiplicar o exército de reserva nos centros urbanos; migrar para as regiões de colonização - em especial na porção Norte do país; assumir a condição de trabalhador volante; ou somar-se aos movimentos de luta pela terra.

Aqueles que se juntaram aos movimentos sociais formaram uma base de resistência, que não aceitava ir para os espaços urbanos, e tampouco se deslocar em direção às frentes de colonização, onde o acesso a terra poderia ser facilitado. Nessa perspectiva, sugiram vários grupos no Brasil, cada um seguindo pautas específicas, porém todos com um objetivo em comum: a terra.

Parte da igreja católica exerceu participação ativa na formação desses movimentos, por meio da CPT - Comissão Pastoral da Terra -, criada na década de 1970 com os objetivos de acompanhar os conflitos agrários e fornecer orientação política e pedagógica aos camponeses (VILLALOBOS; ROSSATO, 1996).

Atualmente, o movimento de maior atuação e expressão no país é o MST Movimento dos Trabalhadores Rurais Sem Terra -, cuja história começou na região Sul, no início da década de 1980. Desde sua formação, o movimento mantém, em sua pauta, a busca por transformações sociais, atuando em um território marcado pela disputa de duas classes antagônicas: latifundiários e camponeses. De acordo com Guimarães (1977, p. 203), os latifundiários são definidos como a classe que:

Por dominar mais da metade de nosso território agrícola [...] absorve e controla muito mais da metade da renda gerada no setor agrário, e controla de fato a política de crédito agrícola, determina e orienta a política de armazenagem e de transporte, a política de preços agrícolas e, em decorrência, a dos preços em geral; influi poderosamente sobre a política governamental de distribuição de favores e facilidades, e canaliza para si as 
subvenções e outros recursos que deveriam encaminhar-se para os setores mais necessitados da agricultura.

$\mathrm{Na}$ atualidade, os latifundiários comandam o agronegócio, sistema reconhecido como uma das maiores expressões do capitalismo no campo. No agronegócio, além dos latifundiários controlarem a posse da terra e a produção nela obtida, utiliza a propaganda para perpetuar a ideia de que são eles quem promove o desenvolvimento econômico quando, na verdade, promovem a desigualdade (FABRINI, 2008).

Já os camponeses formam a classe social que possui um modo de vida especifico caracterizado pelo vínculo com as atividades do campo e pela organização da produção com base no trabalho familiar (MARQUES, 2008).

Oliveira (2007) completa o pensamento de Marques, afirmando que os camponeses são trabalhadores que ao longo da expansão capitalista foram expulsos e expropriados. Assim, se tornaram aqueles que lutam permanentemente para entrar na terra.

Nesse sentido, são os camponeses que traçam a luta pela reforma agrária. As experiências concretizadas se baseiam na constituição dos assentamentos, os quais são conquistados com base na pressão social, que às vezes transforma o campo agrícola "[...] num campo de batalha, pois a espera é longa e a necessidade, urgente. E quem perde é sempre a classe menos favorecida, ou seja, os trabalhadores" (HARACENKO, 2005, p. 6817).

Entre as formas de exercer pressão, utilizadas pelo MST, estão as ocupações de terras que não cumprem a função social, tal como estabelece o Art. 186 da Constituição Federal (BRASIL, 1988), ao determinar que a propriedade rural deve atender aos seguintes requisitos:

\footnotetext{
I - aproveitamento racional e adequado;

II - utilização adequada dos recursos naturais disponíveis e preservação do meio ambiente;

III - observância das disposições que regulam as relações de trabalho;

IV - exploração que favoreça o bem-estar dos proprietários e dos trabalhadores.
}

A Constituição, portanto, garante o direito à propriedade, mas exige que os proprietários cumpram as funções sociais, o que se dá na medida em que se explora racionalmente a terra, respeita as leis trabalhistas e preservando o meio ambiente. Segundo os camponeses do pré-assentamento essas condições não estavam sendo cumpridas pelo proprietário da Fazenda São Paulo, sendo este o ponto que motivou a ocupação da área pelos trabalhadores sem-terra. 


\section{A LUTA PELA TERRA NO PRÉ-ASSENTAMENTO IRMÃ DOROTHY}

Atualmente, no Paraná, existe cerca de 11.000 famílias de acampados, segundo informações fornecidas, em entrevista, pelo Sr. João Flávio Borba da coordenação estadual do MST (informação verbal). Entre estas famílias estão os camponeses do préassentamento Irmã Dorothy, localizado no município de Barbosa Ferraz, na região centroocidental do Paraná, conforme indicam as figuras a seguir (Figuras 1 e 2).

Figura 1 - Localização do município de Barbosa Ferraz

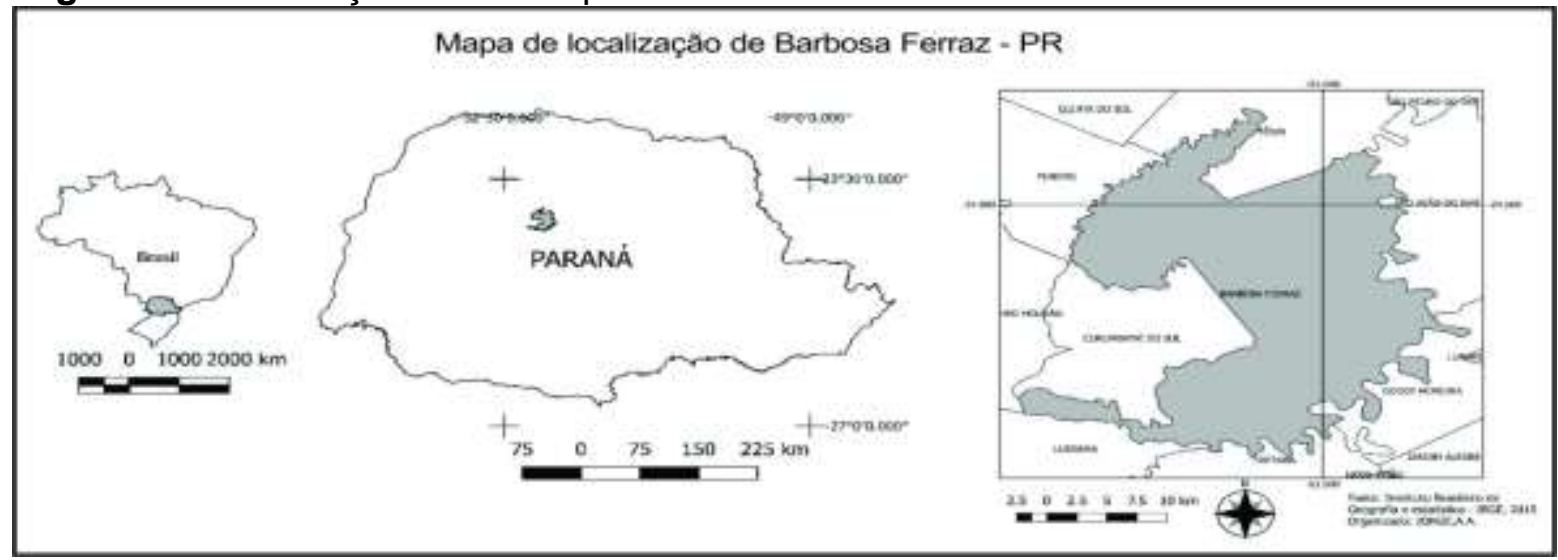

Fonte: Organizado por Jorge, A. A. de: IBGE (2015).

Figura 2 - Localização do pré-assentamento Irmã Dorothy no município de Barbosa Ferraz

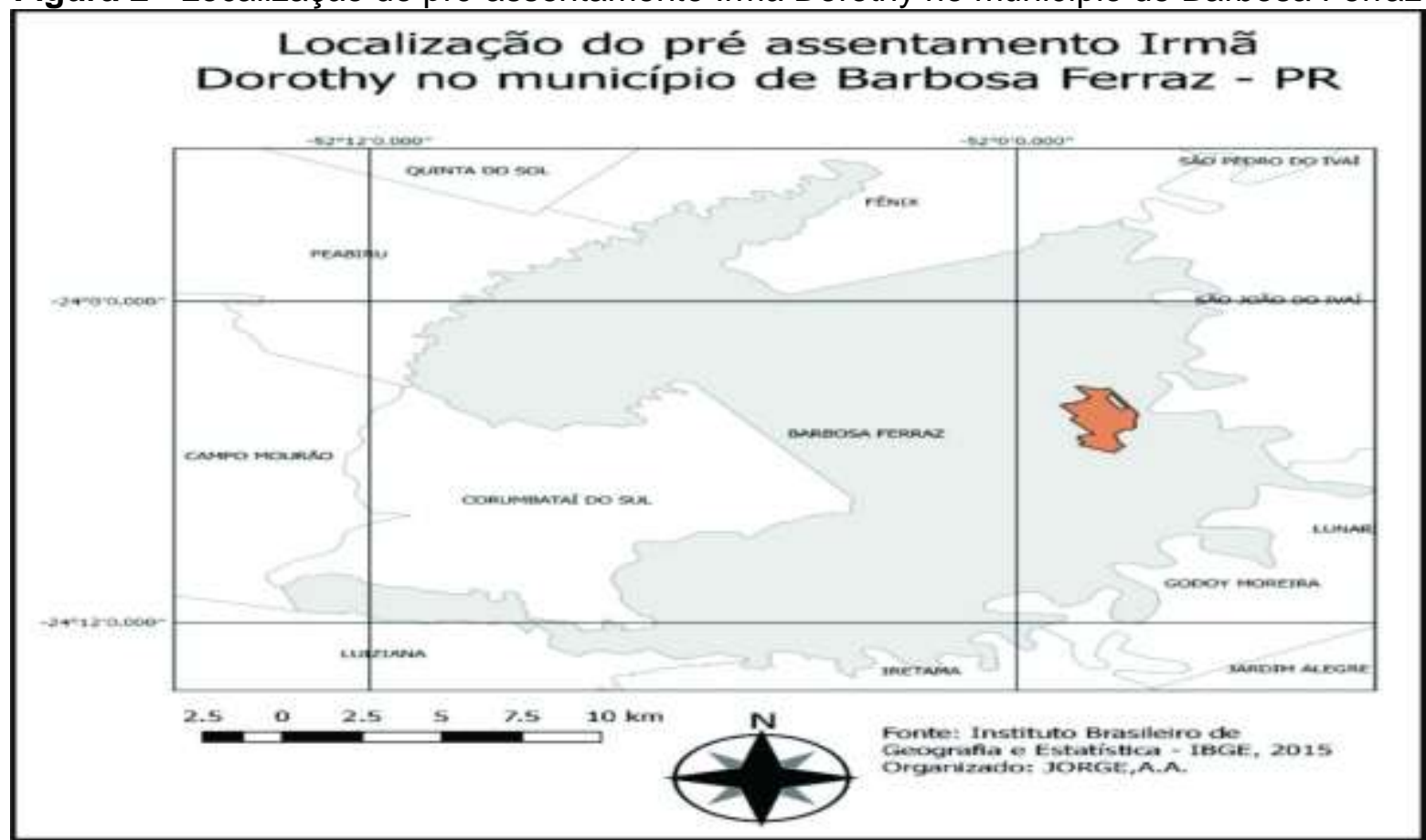

Fonte: Organizado por Jorge, A. A. de: IBGE (2015).

A história do pré-assentamento teve início no ano de 2005, quando aproximadamente 50 famílias do Movimento Sem-Terra ocuparam a área de 573,20 hectares, correspondentes 
à Fazenda São Paulo, ação que, para os camponeses, representa a principal forma de exercer pressão no sentindo de conquistar o acesso a terra (STEDILE; FERNANDES, 2012).

Segundo as entrevistas realizadas junto aos trabalhadores, os problemas que envolviam a propriedade eram baixa produtividade, desmatamento de áreas de preservação ambiental e denúncias de maus tratos aos animais, que, pelas instalações precárias e doenças contraídas, ofereciam risco à região, principalmente pelas suspeitas de foco de febre aftosa.

No entendimento dos camponeses, as condições eram indicativas de que a propriedade não estava cumprindo suas funções sociais, portanto não estava em sintonia com o que é exigido na Constituição e, assim, poderia ser utilizada para fins de reforma agrária.

Como prova do descumprimento da função social, os camponeses utilizam nos processos judiciais documentos que confirmam seus depoimentos com relação à precariedade da propriedade antes da ocupação. Entre estes documentos está o relatório elaborado pelo médico veterinário Antônio Maria Claret Ferrari, que declara ter prestado serviços técnicos à fazenda por mais de três décadas e, em função disto, ter acompanhado o declínio da propriedade ao longo do tempo.

Segundo o relatório do veterinário, a propriedade estava muito degradada, faltavam cercas, curral, chochos e pastagens adequadas e suficientes para a alimentação dos bovinos que, em função do quadro de abandono, estavam morrendo de doenças contraídas e de fome, caracterizando situação de maus-tratos. Parte deste documento é reproduzida na Figura 3.

Figura 3 - Fragmento do laudo técnico sobre as condições da Fazenda São Paulo em período anterior à ocupação, redigido pelo veterinário Antonio Maria Claret Ferrari

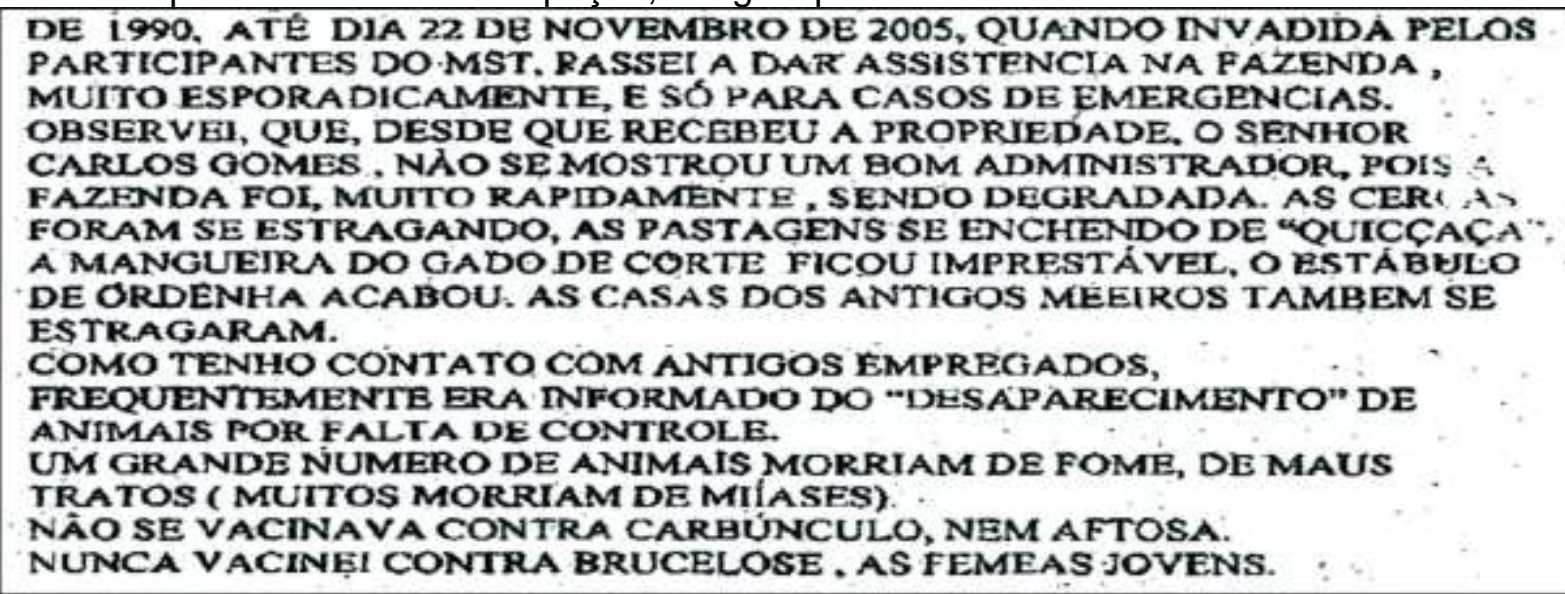

Fonte: Paraná (2005); Comarca de Barbosa Ferraz, documento de 2006. 
Ocupada a área, foram iniciadas as negociações, no sentido de evitar a reintegração de posse. Segundo as informações concedidas em entrevista pelo Sr. Humberto Boaventura Silva Sá (informação verbal), advogado do MST e representante das famílias préassentadas, as fases desse processo, todas já tentadas pelos camponeses, foram as seguintes:

I - Desapropriação sanção:

Essa é a forma mais utilizada nos casos de desapropriação. Delibera que as terras que não estejam cumprindo a função social sejam direcionadas para a reforma agrária. $O$ proprietário recebe o valor da terra nua por meio de Títulos da Dívida Agrária - TDA.

Vale o registro, considerando esse item da fase desapropriatória, de que a propriedade não foi vistoriada pelo INCRA no início da ocupação, procedimento importante para a desapropriação nessa modalidade.

II - Desapropriação por negociação direta com o proprietário:

Tal modalidade acontece quando o proprietário oferta a terra para o INCRA. No caso do pré-assentamento de Barbosa Ferraz, segundo os pré-assentados, algumas vezes o diálogo chegou a ser estabelecido, porém nenhuma negociação foi concretizada, o que gerou momentos de expectativa e frustração nas famílias sem-terra.

III - Desapropriação por interesse social:

Segundo o Sr. Humberto Boaventura "Nenhuma desapropriação por interesse social foi realizada no Paraná para fins de reforma agrária". Tal mecanismo permite que o Estado use todo bem improdutivo, ou cuja utilização não corresponda às necessidades do local de origem, para promover a justa distribuição da propriedade ou o bem-estar social.

Essa modalidade jurídica é o caminho que se trilha no momento, respaldada na relevância da transformação dessa área em assentamento para o povoamento rural e no significado que esse grupo possui para Barbosa Ferraz.

Muitos segmentos da sociedade de Barbosa Ferraz entendem que a permanência dos camponeses na cidade e a efetivação do assentamento é importante, considerando que as famílias contribuem com o município, isto porque, ao mesmo tempo que produzem alimentos que são consumidos pelas pessoas da cidade, geram lucro para o comércio local, resultando em um impacto que é bem-vindo para a economia do município.

Desta forma, existe amplo apoio da sociedade local aos camponeses, o que pode ser comprovado por meio do abaixo-assinado encaminhado ao INCRA, em que os moradores pedem às autoridades que "procedam as negociações necessárias para permanência destas famílias no local e encaminhem o assentamento definitivo" (Figura 4). Ou ainda, por meio do documento redigido pelo Clube dos Diretores Lojistas de Barbosa Ferraz (Figura 5), que manifesta apoio para que o assentamento seja consolidado e destaca que a produção 
dos camponeses no pré-assentamento "fortalece a economia do município e gera empregos diretos e indiretos".

Figura 4 - Abaixo-assinado em apoio às famílias pré-assentadas

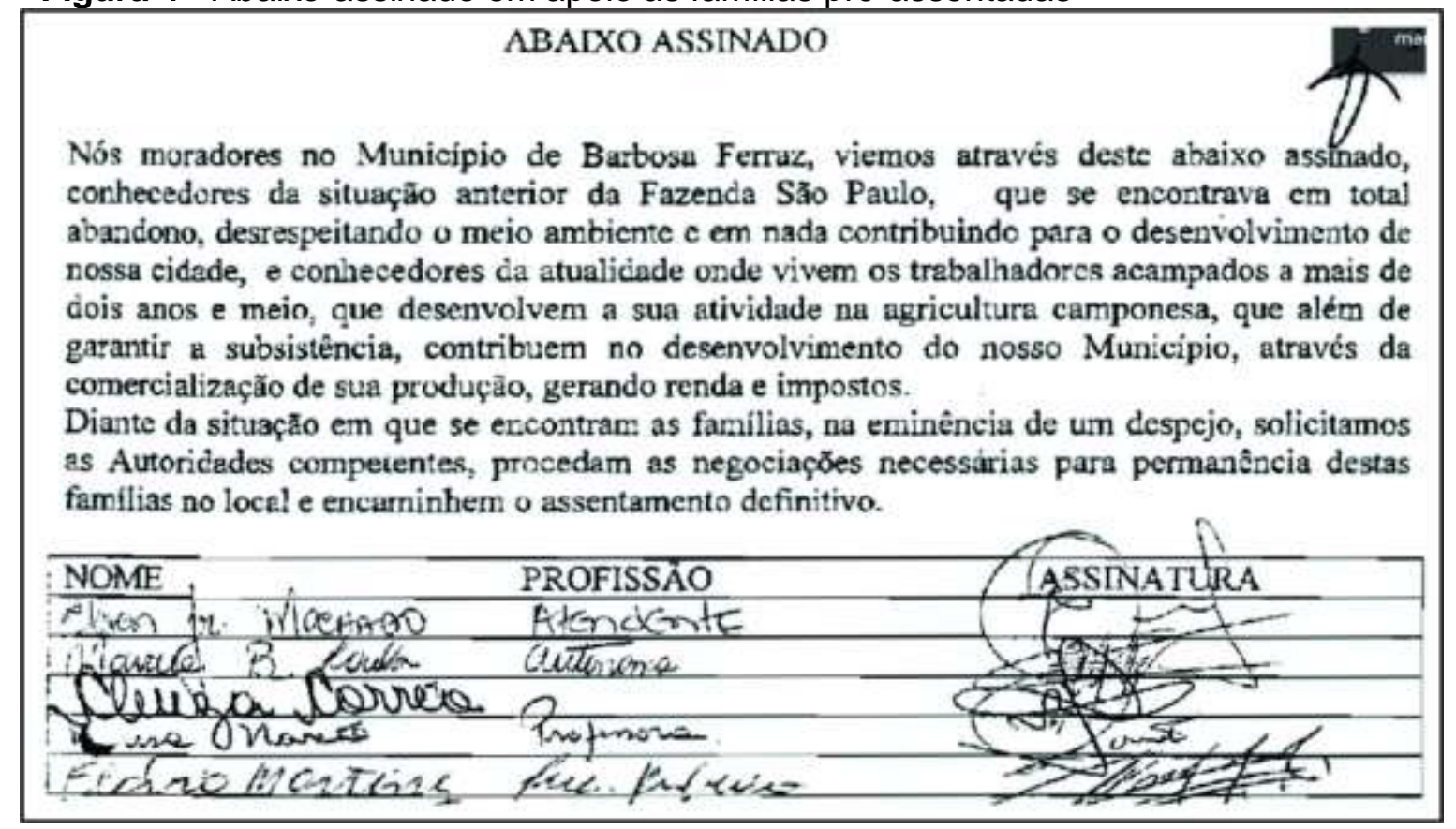

Fonte: Paraná (2005); Comarca de Barbosa Ferraz, documento de 2008.

Figura 5 - Declaração em apoio ao pré-assentamento Irmã Dorothy

\section{DECLARAÇÃO}

\section{Clube dus Diretores I ojistas de Berbose Ferra, vem} deciarar sau gpoio e esforço pera que seje consolidado um assentanento de Reforma Agrária na Fazenda Sao Paulo neste Municipio.

\section{AE 75 famiiü do acumpanenio irmä Dorory estäo inseri-} des aivinnente no comercio. O huoro de sues lavouras st̃o aplicsdos, diretamente no nosso comercio, isso fortalese a economia do Muricipio e gera empregos diretos e indiretos, gerando maior equilibric social, isso consequentemente culine num borm equilibrio de nosso comercio.

Fonte: Paraná (2005); Comarca de Barbosa Ferraz, documento de 2008.

Além destes documentos, existem outros redigidos pela igreja, câmara de vereadores, escolas, sindicatos e associações de bairro. Estes documentos de apoio são utilizados pelos camponeses como uma estratégia para provar que existe interesse da sociedade na efetivação do assentamento.

Enquanto aguardam por uma intervenção do INCRA, no sentido de desapropriar a área ocupada e efetivar o assentamento, os camponeses têm procurado se organizar, 
principalmente com relação à produção. A partir do segundo ano de ocupação, iniciaram o trabalho nas lavouras e o trato dos animais. Numa segunda etapa da organização, resolveram efetivar, por conta própria, a divisão da área ocupada em lotes menores, cada família assumindo a responsabilidade por uma parte.

O parcelamento da área acompanhou o projeto apresentado na Figura 6, que mostra que foram demarcados 33 lotes, distribuídos por sorteio para as 33 famílias pré-assentadas. O tamanho gira em torno de 12 hectares cada, variando de acordo com a declividade do terreno. Cada um destes lotes possui residência e nem todos tem acesso ao curso d'água, desta forma aqueles que não são contemplados garantem o abastecimento por meio das fontes vizinhas e das redes de encanamento construídas pelos próprios pré-assentados.

Figura 6 - A divisão da área do pré-assentamento, realizada pelo próprio MST

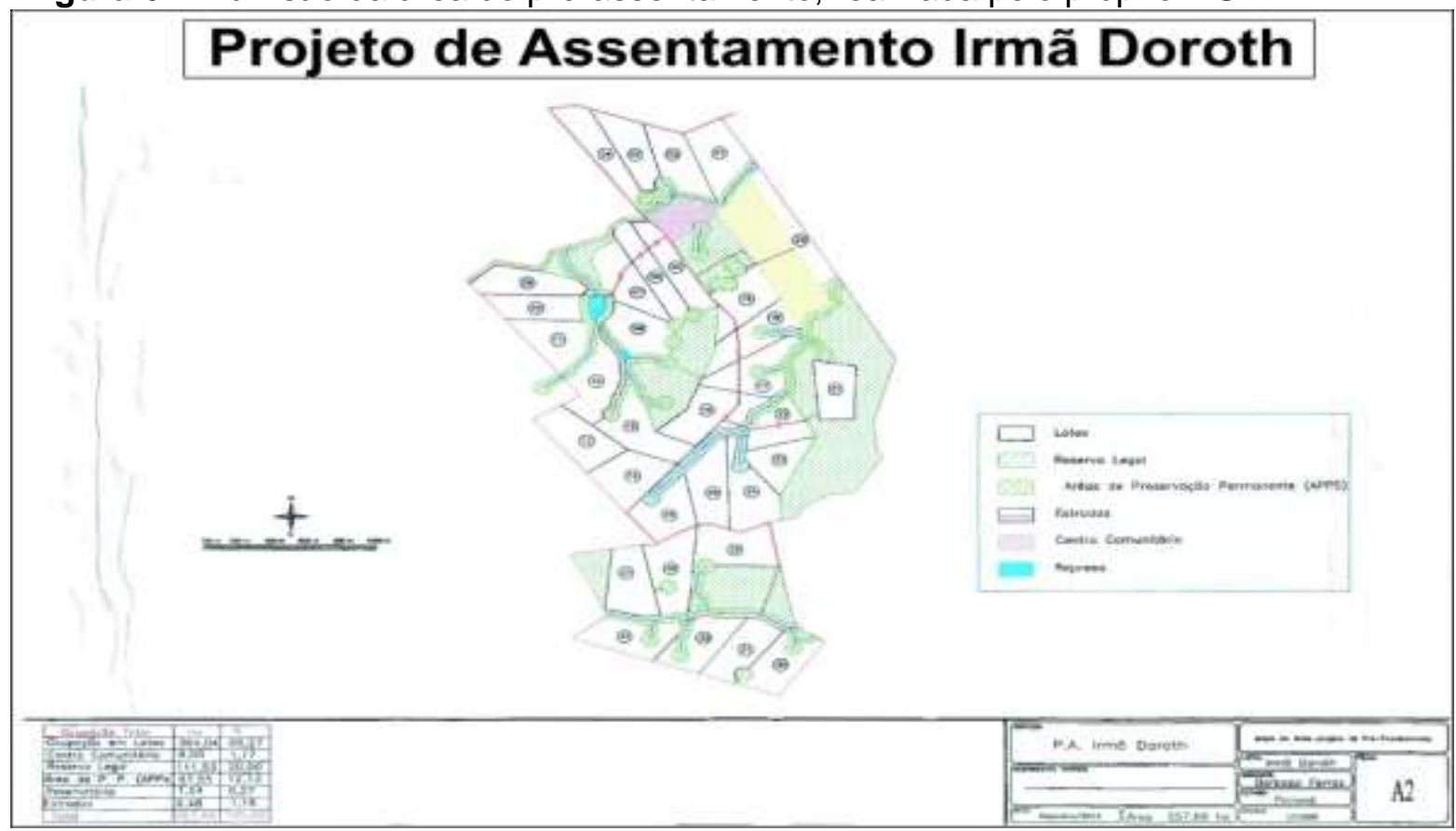

Fonte: Paraná (2005); Comarca de Barbosa Ferraz, documento de 2012.

Os produtores são livres para produzir o que quiserem em seus lotes, e não existe nenhuma espécie de zoneamento agrícola estabelecido pelas famílias. A produtividade geral do pré-assentamento é considerada boa, podendo haver um ou outro caso destoante, em função de que existem trabalhadores mais motivados em investir em suas produções e outros menos, os quais alegam se sentirem desgastados em virtude do longo tempo de ocupação e da falta de respostas do poder público.

Além dos lotes, no projeto desenvolvido pelos trabalhadores consta a separação de áreas de preservação permanente e reserva legal, indicadas pelos tons de verde e também o espaço comunitário, indicado na cor vermelha. Este espaço corresponde à antiga casa 
sede da propriedade, e é o local onde as famílias se reúnem para as assembleias, festas e cerimonias religiosas.

A cor amarela, que não aparece na legenda, indica uma propriedade que geograficamente está inserida na Fazenda São Paulo, mas que não compõe o préassentamento, visto que se trata de uma propriedade que, desde a ocupação, é produtiva e não tem vínculo com o proprietário da área ocupada, possivelmente fruto de algum desmembramento.

A produção é bastante diversificada, no geral são culturas de subsistência: arroz, feijão, milho, mandioca, frutas, hortaliças e leite. Suprida as necessidades das famílias, o excedente é comercializado no próprio município, por meio de intermediários.

A expectativa de continuarem na área da fazenda, na condição de assentados em projeto de reforma agrária, foi frustrada no dia 31 de julho de 2017, quando foi realizada a última audiência de conciliação na Comarca de Barbosa Ferraz. A proposta do proprietário foi que os trabalhadores sem-terra deixassem a área pacificamente até 0 dia $1^{\circ} \mathrm{de}$ novembro do mesmo ano, sem direito a colher as safras pendentes. A advertência foi que, caso não aceitassem sair, seriam despejados por forças policiais.

Os camponeses pediram cinco dias para enviar uma resposta. O prazo foi acatado pelo juiz encarregado do caso, que decidiu ainda: "Consigno que na falta de resposta, com o transcurso do prazo sem manifestação, deverá a ordem judicial, já não suspensa em sede recursal, ser cumprida imediatamente, inclusive com o auxílio da força pública" (Figura 7).

Após discutir em assembleia os resultados da audiência, os pré-assentados formularam sua resposta dentro do período acordado, aceitando a desocupação voluntária até a data estabelecida, desde que o INCRA se responsabilizasse pelo seguinte:

1 A abertura de edital de compra, aquisição de terras na região centro norte do Paraná, ainda no corrente mês de agosto;

2 Que o INCRA pague as despesas de deslocamento das famílias do préassentamento Irmã Dorothy para eventual área ofertada ou outra área escolhida pelas famílias;

3 Que o INCRA indenize as famílias pelo investimento feito no preparo de produção para a safra atual.

O Poder Judiciário se posicionou contrário à manifestação das famílias, alegando que não havia motivos para suspender a decisão de reintegração de posse, muito menos para determinar que o INCRA se responsabilizasse pela realocação. Dessa forma, os camponeses foram intimados a deixar a área até 01 de novembro de 2017, de forma pacífica, caso contrário, estariam expostos ao despejo (Figura 8).

Em janeiro de 2018, já vencido o prazo de desocupação, os camponeses ainda continuavam na Fazenda São Paulo. Esta permanência faz parte da resistência dos 
camponeses, que sabem que depois de ocupar não resta alternativa a não ser a luta permanente pela terra.

Figura 7 - Despacho referente à audiência de conciliação

\section{COMARCA DE BARBOSA FERRAZ \\ VARADA FAZENDA PÚBLCA}

Ao final o $\mathrm{MM}^{\circ}$. Juiz prolatov o seguinte despccho, do qual saíram intimacos todos os presentes: 1. Acoho o sedido constante da "B" acima. 2. Via de consequencio, concedo á parte requerida o prozo de 05 (cincc) dias úteis, na forma solicitado. 3. Consigno que na folta de resposta, com o tronscurso do pıazo sem manifestaçāo, deverá a ordem judicial, já nāo suspensa em sede recursal, ser cumprida imediatamente, hclusive com ॰ auxilio de força pública. 4. Os requeridcs se comprometerr a não plantar ncoda na proprejade invadida, e desde já saem cientes de que nōo terăo direito c qualque safrc a ser colhida posteriormente a dota de $01 / 11 / 2017$, em coso ce aceitaçōo da proposta de acordo írmulada pelos autores. 5. Ultrcpassado o prazo pcra mcnifesaçõo dos requeridos, voltem Imediatamente conclusos os autos. 6. C Ministèrio Fúsíco se compromete ainca a acompcnhar, in loco. qualquer espéće de desocupação voluntória ou coercitiva o ser realizada nestes autos. 7. Que os invasores se ccmprometem quando da saida de propredade, răo depretarem o imóvel em especial a cosc da sede.

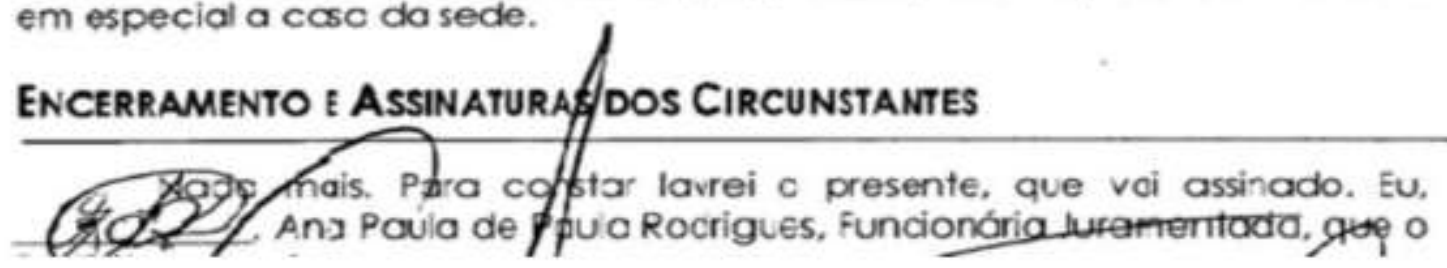

Fonte: Paraná (2005); Comarca de Barbosa Ferraz, documento de 2017.

Figura 8 - Resposta judiciária referente à contraproposta, enviada pelos pré-assentados

Em sendo assim, diante da impossibilidade de desocupaçăo pacifica, determino, pela derradeira vez, a intimaçăo dos integrantes do assentamento para que desocupem voluntariamente os imóveis em questăo até o dia 01 de novembro de 2017.

Decorrido o prazo e năo cumprida a ordem de desocupaçăo na forma voluntária e pacifica, requisite-se o auxilio policial, conforme já determinado em mov. 108 .

Diligências necessárias.

Barbosa Ferraz, datado e assinado digitalmente.

Guilherme Aranda Castro dos Santos

Juiz de Direito

Fonte: Paraná (2005); Comarca de Barbosa Ferraz, documento de 2017.

Outra condição que contribui para tal situação é que a reintegração de posse, determinada pelo poder judiciário, ainda não foi cumprida pelo Estado, o que pode ser 
justificado pelo elevado custo e a dificuldade em realizar este tipo de operação, sobretudo sem que haja confontro entre sem-terras e policiais.

Depois de 12 anos de ocupação, os camponeses afirmavam que não desistiriam de transformar a área em assentamento, o que representa uma transformação na estrutura social de uma fração do campo, que permite a eles apropriar-se "[...] dos frutos de seu próprio trabalho" (SILVA, 1985, p. 93). Sempre quando questionados sobre o que fariam, caso a reintegração de posse se efetivasse, a resposta era uma só: "ocupar novamente".

\section{CONSIDERAÇÕES FINAIS}

Com base no exposto, existem quatro pontos que ajudam a entender a estrutura agrária brasileira:

I - Desde a colonização, o país assumiu o papel de fornecedor de gêneros para o mercado externo, o que serviu como argumento para a formação do latifúndio;

II - os mecanismos de distribuição de terras excluíram o camponês, sobretudo com o advento da modernização agrícola, que representou enraizamento do capitalismo na agricultura, trazendo uma porção de desdobramentos, tais como a expropriação, a marginalização e a transformação do homem do campo em proletário urbano;

III - a exclusão dos camponeses refletiu na luta organizada, processo que contou com segmentos da Igreja Católica, e que conseguiu avançar para a formação de movimentos sociais como o MST;

IV - o grito dos trabalhadores expulsos da terra é pela reforma agrária, que esbarra no papel antagônico do Estado, o qual age em conveniência com os interesses de grupos políticos que exercem poder por meio da dominação de recursos econômicos.

Nessa conjuntura, se a reforma agrária não acontece como deveria, de cima para baixo, são os trabalhadores sem-terra que a empurram de baixo para cima. Os assentamentos representam a luta social convertida em espaço.

Essa trajetória de conquista de território muitas vezes é longa e passa pela ocupação da terra, como no caso das famílias do pré-assentamento Irmã Dorothy, que ocupam e resistem em busca da transformação da área em assentamento.

As famílias pré-assentadas passam pelo medo de uma reintegração de posse que pode ocorrer a qualquer momento e o que as mantém ainda naquela terra é a necessidade de retornar ao campo, o que representa a conquista de autonomia.

\section{REFERÊNCIAS}

BRASIL. Constituição (1988). Constituição da República Federativa do Brasil de 1988. Disponível em: 
<http://www.planalto.gov.br/ccivil_03/constituicao/constituicaocompilado.htm>. Acesso em: 15 dez. 2017.

FABRINI, J. E. Latifúndio e agronegócio: semelhanças e diferenças no processo de acumulação de capital. Revista Pegada, Presidente Prudente, v. 9, n. 1, p. 35 - 62, jun. 2008.

FLEISCHFRESSER, V. Modernização tecnológica da agricultura: contrastes regionais e diferenciação social no Paraná da década de 70. Curitiba: Livraria do Chain, 1988.

GUIMARÃES, A. P. Quatro séculos de latifúndio. Rio de Janeiro: Paz e Terra, 1977.

HARACENKO, A. A. S. A história da reforma agrária e da luta pela terra no noroeste do Paraná: um estudo de caso em Querência do Norte. In: ENCONTRO DE GEÓGRAFOS DA AMÉRICA LATINA, 10., 2005, São Paulo. Anais... São Paulo: USP, 2005. p. 6814 - 6835.

IBGE. Bases e referências. 2015. Disponível em: <https://mapas.ibge.gov.br/bases-ereferenciais/bases-cartograficas/malhas-digitais>. Acesso em: 21 jan. 2018.

MARQUES, M. I. M. A atualidade do uso do conceito de camponês. Revista Nera, Presidente Prudente, ano 11, n. 2, p. 57 -67, jan./ jun. 2008.

OLIVEIRA, A. U. Modo capitalista de produção, agricultura e reforma agrária. São Paulo: Ed. FFLCH, 2007.

PARANÁ. Comarca de Barbosa Ferraz. Ação de Reintegração de Posse n $0000142-$ 54.2005.8.16.0051. Vara da Fazenda Pública de Barbosa Ferraz. Autor: Carlos Alberto Consoni Gomes. Réu: Movimento dos Trabalhadores Sem Terra - MST. Barbosa Ferraz, PR, 30 de novembro de 2005.

PRADO JÚNIOR, C. História econômica do Brasil. São Paulo: Brasiliense, 1983, p. 15 105.

SERRA, E. Colonizacão, uso da terra e conflitos rurais no Paraná. In: ENCUENTRO DE GEÓGRAFOS DE AMÉRICA LATINA, 12., 2009, Montevidéo. Anais... Montevidéo: Universidad de le república del Uruguay, 2009. v. 1, p. 1 - 26.

SERRA, E. Os primeiros processos de ocupação da terra e a organização pioneira do espaço agrário do Paraná. Boletim de Geografia, Maringá, ano 10, n. 1, p. 61 - 93, 1992.

SILVA, J. G. O que é questão agrária. São Paulo: Brasiliense, 1985.

SILVA, J. G. A modernização dolorosa: estrutura agrária, fronteira agrícola e trabalhadores rurais no Brasil. Rio de Janeiro: Zahar,1981.

STEDILE, J. P.; FERNANDES, B. M. Brava gente: a trajetória do MST e a luta pela terra no Brasil. São Paulo: Expressão Popular, 2012.

VILLALOBOS, J. G. U.; ROSSATO, G. A comissão pastoral da terra (CPT): notas da sua atuação no Estado do Paraná. Boletim de Geografia, Maringá, v. 14, n. 1, p. 19 - 31, 1996.

Recebido: fevereiro de 2018. Aceito: agosto de 2018.

\footnotetext{
'Cabe citar que este trabalho é oriundo de uma pesquisa de mestrado, que está em desenvolvimento, e é financiada pela CAPES - Coordenação de Aperfeiçoamento de Pessoal de Nível Superior.
} 